\title{
Patient-centred care
}

THANK YOU FOR YOUR RECENT EDITORIAL ${ }^{1}$ WITH ITS ENTERtaining and informative example of patient-centred care (PCC). (Since I already serve ethically sourced coffee and have lovely plants, the only thing lacking in my practice seems to be a leather sofa....)

I do position myself as a PCC provider, so I started to think of my own patient interactions that could exemplify "a professional obligation to take responsibility for, and provide care targeted to, the individual patient's needs."

Like most community pharmacies, I provide weekly pill pack medications that aim to increase ease of adherence to the chosen drug therapy. But what if the patient is consistently not able to access their pill packs, resulting in (undisclosed) undertreatment?

$\mathrm{CH}$, a 47-year-old woman with fibromyalgia, hypertension, hypercholesterolemia, depression and restless leg syndrome, came into the pharmacy with her 12-year-old daughter to pick up her 4-week pill packs. Previously, we had provided $\mathrm{CH}$ with a separate bedtime pill pack, since her bedroom was on the second storey of their home and her pill pack was usually left in the kitchen (to facilitate better adherence of other medications). $\mathrm{CH}$ reported the separate bedtime pill pack to be extremely useful.

Upon reviewing the contents of her current pill pack, $\mathrm{CH}$ 's daughter disclosed that her mother's supper pills were often "left over." CH explained that it was difficult to remember to take the supper pills and that they were often skipped. The medications that were intended for supper dosing were as follows:

- Ramipril 10 mg (1 of 2 daily doses)

- Nifedipine XL 20 mg (entire daily dose)

- Rabeprazole 20 mg (1 of 2 daily doses)

- Pregabalin $50 \mathrm{mg}$ (1 of 3 daily doses)

Undertreatment of her hypertension was my first concern. Although $\mathrm{CH}$ did not have time for me to take her blood pressure, I did request that we check it at her next visit. She did admit to not feeling the "greatest" and sleeping poorly. I also inquired about her previous stomach complaints. $\mathrm{CH}$ reported that the rabeprazole was to treat belching following eating meat, which had neither gotten worse or better since the physician initiated the treatment and even increased the dose from every day to twice a day, although many of the second doses were admittedly missed.
I reviewed the supper dosing with $\mathrm{CH}$ and asked if she would be agreeable to switching the medications over to bedtime if it was reasonable to do so. $\mathrm{CH}$ agreed, and I called the physician to discuss CH's medication management. According to the physician, CH's blood pressure (as per clinic visits) had not been well controlled, so the physician agreed to institute my changes before increasing doses or adding any new medications. CH's objective and subjective symptoms would be reviewed at the next clinic visit, as well as at the next pharmacy visit.

The following were the changes made for $\mathrm{CH}$ :

- Ramipril $10 \mathrm{mg}$ AM and supper changed to AM and before bedtime

- Nifedipine XL $20 \mathrm{mg}$ at supper changed to before bedtime

- Rabeprazole $20 \mathrm{mg}$ AM and supper changed to once a day, since it had not been any more effective for her "burping" after meat consumption with the twice-a-day dosing

- Pregabalin $50 \mathrm{mg}$ AM, supper and before bedtime changed to $50 \mathrm{mg} \mathrm{AM}$ and $100 \mathrm{mg}$ before bedtime

Follow-up with $\mathrm{CH}$ on adherence and disease management is still pending.

I feel that this scenario is a good example of listening to the patient's needs and creating medication management techniques that are better suited to the individual while still optimizing pharmacological effectiveness. There are more glamorous examples of patient-centred care, but this is a simple example of potentially preventing unnecessary increases in medication therapy.

\section{Lisa Zaretzky, BScPharm, PharmD Apothecary of Morden Inc. Morden, Manitoba}

PS: I also really appreciated the literature review on the top 5 cardiology studies from 2011 to 2012. I do hope you provide us with more!

\section{Reference}

1. Tsuyuki RT, Krass I. What is patient-centred care? Can Pharm J (Ott) 2013;146:177-8. 